\title{
Dietary diversity during infancy and the association with childhood food allergen sensitization
}

\author{
Kate Maslin ${ }^{1}$, Kaci Pickett ${ }^{2}$, Suzanne $\mathrm{Ngo}^{2}$, William Anderson ${ }^{2}$, Taraneh Dean ${ }^{3}$, and \\ Carina Venter ${ }^{4}$ \\ ${ }^{1}$ University of Plymouth \\ ${ }^{2}$ University of Colorado Denver School of Medicine \\ ${ }^{3}$ University of Brighton \\ ${ }^{4}$ Children's Hospital Colorado
}

April 7, 2021

Dietary diversity during infancy and the association with childhood food allergen sensitization

Authors: Kate Maslin $\mathrm{PhD}^{1,2}$, Kaci Pickett $\mathrm{MSc}^{3}$, Suzanne $\mathrm{Ngo}^{3,4} \mathrm{MD}$, William Anderson ${ }^{3,4} \mathrm{MD}$, Taraneh Dean $\mathrm{PhD}^{2,5}$, Carina Venter $\mathrm{PhD}^{2,3,4}$

1. School of Nursing and Midwifery, University of Plymouth, Plymouth, UK.

2. The David Hide Asthma and Allergy Centre, St. Mary's Hospital, Isle of Wight, UK

3. University of Colorado School of Medicine, Colorado, USA

4. Allergy and Immunology Section, Children's Hospital Colorado, Colorado, USA

5. University of Brighton, Brighton, UK

Running title: Dietary diversity and food sensitization

\section{Corresponding author:}

Dr. Carina Venter, Section of Allergy \& Immunology, University of Colorado School of Medicine | Children's Hospital Colorado, Children's Hospital Colorado | 13123 East 16th Avenue, Box B518 | Anschutz Medical Campus | Aurora, CO 80045 Phone: (720) 777-6844 | Fax: (720) 777-7247 | Carina.Venter@childrenscolorado.org

Word count:1284

Number of tables and figures : 2 tables, 1 figure, 1 table in supplementary file

Conflict of interest:

CV provided lecture material and/or consultancy to Abbott Laboratories, Mead Johnson Nutritionals, Nestle Nutrition Institute, DBV technologies, Danone, Li'l Mixins and Reckitt Benckiser.

All other authors declare no conflict of interest relevant to this manuscript.

Financial support: The UK Food Standards Agency funded years 1-3 of the FAIR study (ref T0703). The 10-year follow up was funded by the National Institute of Health Research, UK. The researchers acted independently of the funders.

Key words: Food sensitization, dietary diversity 
To the Editor,

'Dietary diversity' (DD), is defined as the number of different foods or food groups consumed over a given reference period $^{1}$. A report from the European Academy of Asthma, Allergy and Immunology found that increased DD may reduce the risk for development of food and aero-allergen sensitization via its effect on the microbiome and increased intake of immune-modulatory nutrients ${ }^{2}$. The report summarized 14 papers reporting the role of DD on allergy outcomes. Only two studies reported on the association between increased DD and food allergen sensitisation ${ }^{3,4}$, one of which found a reduced risk ${ }^{4}$. One study reported an association between increased DD and decreased aero-allergen sensitization ${ }^{4}$.

The aim of this study is to assess the effect of DD in the first year of life on food and aero allergen sensitization over the first ten years of life in a population birth cohort.The Food Allergy and Intolerance Research (FAIR) birth cohort included children born on the Isle of Wight (UK) $(n=969)$ between 2001-2002 who were followed up prospectively ${ }^{3}$. Demographic and reported familial allergy data were collected at 12 weeks gestation using the validated ISAAC questions ${ }^{4}$. Infant and child allergy data was collected at 3,6, 9 months and 1, 2, 3 and 10 years.

Food introduction data were collected via a standardized questionnaire at ages 3,6 , and 9 months ${ }^{5}$. Specific information was collected regarding breastfeeding duration, introduction of infant formula feeding and age of introduction of 21 foods categorized at the same time periods ${ }^{7}$. The 21 foods were fruits (citrus fruit, non-citrus fruit, strawberries, tomato), vegetables, potato, pulses, non-wheat cereals (rice, oats), meat (chicken/turkey, lamb, beef, pork) and food allergens (cows' milk products, egg, wheat, peanut, tree nuts, fish, soy and sesame). DD was calculated as the number of foods introduced by 3,6 , and 9 months. Cumulative DD was calculated as the number of different foods eaten by 6 months plus number of foods eaten by 9 months $^{6,7}$. Portion size and frequency of intake data was not available.

Skin prick tests (SPT) were performed to milk, wheat, egg, cod, peanut and sesame at 1, 2, 3 and 10 years. A new variable was calculated for children diagnosed with any food sensitization in the first ten years of life ("over the first ten years"). The following aeroallergens were tested via SPT at the same time points: house dustmite, cat and grass. Ethical approval was obtained from the NRES South Central - Southampton B Research Ethics Committee (REF 10/H0504/11). All parents consented and children provided assent.

Data were double entered on SPSS versions 20 and 21 (SPSS Inc, Chicago, USA). Descriptive statistics with means (standard deviations) or counts (frequencies) were calculated. Univariate analysis was carried out to assess the associations between DD, food and aero allergen sensitization. Logistic regression models were fitted to describe the relationship between the binary food sensitization variables, DD and other related covariates. If independent variables (family history of allergic disease, maternal history of food sensitization and food allergy, parity, maternal smoking prior to pregnancy, breastfeeding duration, timing of introduction of solid foods, and any eczema in the first year of life) were found to be statistically significant at the $\mathrm{p}=0.05$ level in the univariate analysis, the variables were entered into a multivariate model to understand the variables at each time point that are independently associated with food sensitization in the first 10 years of life. Spearman correlations were performed to examine relationships between count data. All significance tests were two sided and analyses were performed with SAS version 9.4 (SAS Institute Inc., Cary, NC, USA). We made no adjustments for multiple comparisons because the hypotheses were made a priori .

Data was available on 851 mother-infant dyads, for whom we had information on DD, food and aero allergen sensitization on at least one occasion up to 10 years of age. There were $763(89.7 \%)$ children with data at 1 year, $658(77.3 \%)$ at 2 years, $670(78.7 \%)$ at 3 years and $589(69.2 \%)$ at 10 years. Demographic, environmental and allergic characteristics are shown in Table 1.

The DD by 3, 6 and 9 months was 0 (IQR 0), 11 (IQR 9-13) and 16 (IQR 14-17). Cumulative DD at 6+9 months was 27 (IQR 24-30). Table 2 shows the univariate results for the associations between DD and food sensitization at each time point. A higher DD at 6 months decreased the odds of food sensitization at 1 year (OR $0.86,95 \%$ CI $0.74-1.0, \mathrm{p}=0.04$ ), 2 years (OR 0.84, 95\%CI $0.73-0.96, \mathrm{p}=0.01$ ) and over the first 10 years combined (OR 0.92, 95\% CI 0.88-0.98, p=0.01). Likewise, a higher DD at 9 months decreased the odds of 
food sensitization at 2 (OR 0.81, 95\%CI 0.67-0.98), $\mathrm{p}=0.03$ ) and 3 years (OR 0.83, 95\% CI 0.7-0.98, $\mathrm{p}=0.03$ ) (Figure 1). A higher cumulative DD (6+9 months) decreased the odds of food sensitization at 1, 2 and 3 years. There was no association between DD at any age and food sensitization at 10 years.

Looking at covariates, maternal history of food sensitization, parity, maternal prenatal smoking, later introduction of solid foods and eczema in the first year of life were associated with food sensitization at one or more time periods (supplementary file 1). In the multivariate model (Table 2) a higher DD at 6 months decreased the odds of food sensitization at 1 year (OR 0.79, 95\% CI 0.65-0.96, $\mathrm{p}=0.02$ ) and 2 years (OR 0.84, $95 \%$ CI $0.73-0.96, \mathrm{p}=0.01)$. A higher DD at 9 months decreased the odds of food sensitization at 2 years (OR $0.79,95 \%$ CI 0.65-0.96, $\mathrm{p}=0.02$ ), but not at any other age. A higher cumulative DD decreased the odds of food sensitization at 1 and 2 years. There was no association between DD at any age and aeroallergen sensitization at any age (data not shown).

Overall our data demonstrates a reduced risk of food sensitization up to 2 years of age in those consuming a higher diversity of foods in the first 6-9 months of life. On the whole, the association was maintained when relevant confounding variables were accounted for, but was not apparent at age 10 in either the univariate or multivariate analyses. This aligns to some extent with research by Roduit et al. ${ }^{6}$ and Markevyech et al. ${ }^{8}$, who used similar methods and study designs, thus adding support to the evidence base promoting dietary exposure in early life to prevent food allergy, rather than dietary avoidance.

Roduit et al. ${ }^{6}$, included participants from 5 European countries, with a similar sample size $(\mathrm{n}=856)$ to the FAIR cohort. They assessed intake of a smaller number of foods (between 6-15) with children followed up at 4.5 and 6 years. In addition to a reduced risk of food sensitization, they also found that increasing infant DD was protective of asthma and was positively associated with increased expression of a marker for regulatory $\mathrm{T}$ cells, providing a plausible mechanism. Markeyvech et $\mathrm{al}^{8}$, using data from the German LISA cohort $(n=2518)$, reported higher infant DD was associated with decreased risk of allergic sensitization to aeroallergens up to age 15 years among children with early skin symptoms. It is not clear why in the FAIR cohort, the reduced risk of food sensitization exists until age 2, but not until age 10, as in the case of clinical food allergy ${ }^{9}$, or why we did not find an association with aeroallergen sensitization. This may be due to a more pronounced effect on the microbiome in the first 1-3 years of life than in later childhood ${ }^{10}$. Early life microbiome has particularly been associated with early life food allergen sensitization ${ }^{11}$. Differences in aeroallergen sensitization may be due to different range of allergens tested.

Strengths of this study are the prospective design, large numbers of foods considered and low attrition rate. Although we considered a range of confounding variables, there may be unknown or unmeasured factors that we have not explored. In summary, higher food diversity during the first 6-9 months of life is associated with a decreased risk of food allergic sensitization up to 2 years of age in adjusted models and up to 3 years of age in unadjusted models in our population based cohort.

Kate Maslin $\mathrm{PhD}^{1,2}$,

Kaci Pickett $\mathrm{MSc}^{3}$,

Suzanne $\mathrm{Ngo}^{3,4} \mathrm{MD}$,

William Anderson ${ }^{3,4} \mathrm{MD}$,

Taraneh Dean $\mathrm{PhD}^{2,5}$,

Carina Venter $\mathrm{PhD}^{2,3,4}$

1.School of Nursing and Midwifery, University of Plymouth, Plymouth, UK.

2.The David Hide Asthma and Allergy Centre, St. Mary's Hospital, Isle of Wight, UK

3.University of Colorado School of Medicine, Colorado, USA

4.Allergy and Immunology Section, Children's Hospital Colorado, Colorado, USA 
5.University of Brighton, Brighton, UK

Acknowledgements: We thank all the FAIR study participants and families for their participation over the years.

Impact statement: Higher food diversity during the first 6-9 months of life is associated with a decreased risk of food allergic sensitization up to 2 years of age in adjusted models and up to 3 years of age in unadjusted models, providing further evidence that a varied infant diet should be encouraged.

\section{References}

1. Ruel MT. IS DIETARY DIVERSITY AN INDICATOR OF FOOD SECURITY OR DIETARY QUALITY? A REVIEW OF MEASUREMENT ISSUES AND RESEARCH NEEDS. International Food Policy Research Institute 2002:1-58.

2. Venter C, Greenhawt, M, Meyer, R, Agostoni, C, Nwaru, G, Roduit, C, Utersmeyer, E, Akdis, C, Poulsen, L., Roberts, G, Adel-Patient, Agache, I, Grimshaw K, Bischoff, S, Du Toitm G, Feeney, M, Garn, H, Frei, R, Sommer-Gruberbeir, K, Mills, C. Muraro, A, Maslin, K, Lunjani, N, Palli, I, Reese, I, Renz, H, Palmer, D, Smith, P, Smolinska, S, Sokolowska, M, Stanton, C, Vlieg-Boerstra, B, O'Mahony, L. EAACI position paper on diet diversity in pregnancy, infancy and childhood: Novel concepts and implications for studies in allergy and asthma. Allergy 2019;In press.

3. Venter C, Patil V, Grundy J, et al. Prevalence and cumulative incidence of food hypersensitivity in the first ten years of life. Pediatr Allergy Immunol 2016.

4. von Mutius E. Epidemiology of asthma: ISAAC-International Study of Asthma and Allergies in Childhood. Pediatr Allergy Immunol 1996;7:54-6.

5. Venter C, Pereira B, Voigt K, et al. Factors associated with maternal dietary intake, feeding and weaning practices, and the development of food hypersensitivity in the infant. Pediatr Allergy Immunol 2009;20:320-7.

6. Roduit C, Frei R, Depner M, et al. Increased food diversity in the first year of life is inversely associated with allergic diseases. J Allergy Clin Immunol 2014;133:1056-64.

7. Nwaru BI, Takkinen HM, Kaila M, et al. Food diversity in infancy and the risk of childhood asthma and allergies. J Allergy Clin Immunol 2014;133:1084-91.

8. Markevych I, Standl M, Lehmann I, von Berg A, Heinrich J. Food diversity during the first year of life and allergic diseases until 15 years. J Allergy Clin Immunol 2017.

9. Venter C, Maslin K, Holloway JW, et al. Different Measures of Diet Diversity During Infancy and the Association with Childhood Food Allergy in a UK Birth Cohort Study. J Allergy Clin Immunol Pract 2020.

10. Jandhyala SM, Talukdar R, Subramanyam C, Vuyyuru H, Sasikala M, Nageshwar Reddy D. Role of the normal gut microbiota. World J Gastroenterol 2015;21:8787-803.

11. Azad MB, Konya T, Guttman DS, et al. Infant gut microbiota and food sensitization: associations in the first year of life. Clin Exp Allergy 2015;45:632-43.

Table I. Participant demographic characteristics of the whole FAIR cohort

Characteristic (total number)

Male $(\mathrm{n}=849)$

Number of participants first born in family $(\mathrm{n}=851)$

Type of delivery $=$ Vaginal $(\mathrm{n}=848)$

Family history of allergy at recruitment; asthma, eczema, rhinitis, food allergy $(\mathrm{n}=851)$

Maternal history of allergy at recruitment; asthma, eczema, rhinitis, food allergy $(\mathrm{n}=851)$

Maternal FA at recruitment $(\mathrm{n}=851)$ 
Characteristic (total number)

Maternal smoking prior to pregnancy $(\mathrm{n}=831)$

Maternal education at recruitment $(\mathrm{n}=851)$ No education Secondary school education (up to 16 years of age) Post second

Median breastfeeding duration in days (IQR)

Any breastfeeding; even just 1 feed $(\mathrm{n}=846)$

Median age of introduction of solid foods in weeks (IQR)

Number of infants introducing solids by 3 months $(\mathrm{n}=834)$

Median age of introduction of infant formula in days (IQR)

Eczema at 3 months $(\mathrm{n}=825)$

Eczema at 6 months $(\mathrm{n}=826)$

Eczema at 12 months $(\mathrm{n}=831)$

Food SPT at 1 year $(\mathrm{n}=763)$

Food SPT at 2 years $(\mathrm{n}=658)$

Food SPT at 3 years $(\mathrm{n}=670)$

Food SPT at 10 years $(\mathrm{n}=589)$

Any food SPT over the first 10 years of life $(n=851)$

Specific IgE at 10 year $(\mathrm{n}=246)$

SPT: Skin prick test

Table: 2 Measures of diet diversity vs. food allergen sensitization over the first 10 years of life using univariate and multivariate analysis

\begin{tabular}{|c|c|c|c|}
\hline Univariate analysis & Univariate analysis & $\begin{array}{l}\text { Univariate analysis } \\
\text { OR }(95 \% C I)\end{array}$ & $\begin{array}{l}\text { Univariate analysis } \\
p \text {-value }\end{array}$ \\
\hline \multirow{5}{*}{$\begin{array}{l}\text { Diet diversiry at } 3 \\
\text { months }\end{array}$} & 1 year & $1.04(0.72,1.49)$ & 0.84 \\
\hline & 2 years & $0.92(0.6,1.41)$ & 0.7 \\
\hline & 3 years & $0.78(0.45,1.38)$ & 0.4 \\
\hline & 10 years & $1.01(0.82,1.24)$ & 0.93 \\
\hline & Over first 10 years & $0.93(0.76,1.15)$ & 0.52 \\
\hline \multirow{5}{*}{$\begin{array}{l}\text { Diet diversity by } 6 \\
\text { months }\end{array}$} & 1 year & $0.86(0.74,1)$ & 0.04 \\
\hline & 2 years & $0.84(0.73,0.96)$ & 0.01 \\
\hline & 3 years & $0.89(0.79,1.01)$ & 0.07 \\
\hline & 10 years & $0.94(0.88,1.01)$ & 0.11 \\
\hline & Over first 10 years & $0.92(0.86,0.98)$ & 0.01 \\
\hline \multirow{5}{*}{$\begin{array}{l}\text { Diet diversity by } 9 \\
\text { months }\end{array}$} & 1 year & $0.83(0.67,1.03)$ & 0.09 \\
\hline & 2 years & $0.81(0.67,0.98)$ & 0.03 \\
\hline & 3 years & $0.83(0.7,0.98)$ & 0.03 \\
\hline & 10 years & $1.05(0.94,1.18)$ & 0.37 \\
\hline & Over first 10 years & $1(0.9,1.1)$ & 0.94 \\
\hline \multirow{5}{*}{$\begin{array}{l}\text { Cumulative diet diversity } \\
(6+9 \text { months })\end{array}$} & 1 year & $0.9(0.81,1)$ & 0.04 \\
\hline & 2 years & $0.88(0.81,0.97)$ & 0.01 \\
\hline & 3 years & $0.92(0.84,0.99)$ & 0.03 \\
\hline & 10 years & $0.98(0.94,1.04)$ & 0.53 \\
\hline & Over first 10 years & $0.96(0.89,1.02)$ & 0.18 \\
\hline
\end{tabular}




\section{Multivariate analysis (only including factors that have shown significance in the univariate analysis) Diet diversity by 6 months}

Diet diversity by 9 months

\begin{tabular}{|c|c|}
\hline \multirow{3}{*}{$\begin{array}{l}\text { Cumulative diet diversity } \\
(6+9 \text { months })\end{array}$} & 3 years $^{\$ \$}$ \\
\hline & 1 year* \\
\hline & $\begin{array}{l}2 \text { years }^{\&} \\
3 \text { years }^{\$ \$}\end{array}$ \\
\hline
\end{tabular}

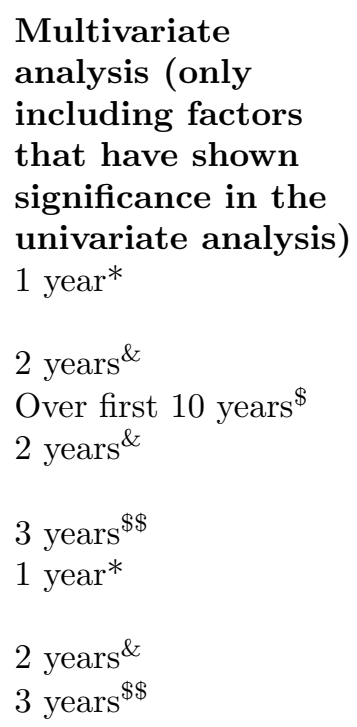

$\begin{array}{ll}\begin{array}{l}\text { Multivariate } \\ \text { analysis (only } \\ \text { including factors } \\ \text { that have shown } \\ \text { significance in the } \\ \text { univariate analysis) } \\ 0.79(0.65,0.96)\end{array} & \begin{array}{l}\text { Multivariate } \\ \text { analysis (only } \\ \text { including factors } \\ \text { that have shown } \\ \text { significance in the } \\ \text { univariate analysis) } \\ 0.02\end{array} \\ 0.84(0.73,0.96) & 0.01 \\ 0.94(0.87,1.01) & 0.11 \\ 0.79(0.65,0.96) & 0.02 \\ 0.87(0.71,1.05) & 0.15 \\ 0.87(0.76,0.98) & 0.03 \\ 0.88(0.8,0.97) & 0.01 \\ 0.95(0.87,1.05) & 0.31\end{array}$

*corrected for age of introduction of solids, weight for age z-score, parity, maternal history of allergy, type of delivery and eczema at 3 months.

\& corrected for parity, maternal history of allergy, maternal smoking prior to pregnancy, and eczema in $1^{\text {st }}$ year.

$\$$ corrected for age of introduction of solid foods, breastfeeding duration ,parity, maternal history of allergy, maternal smoking prior to pregnancy, and eczema in $1^{\text {st }}$ year.

$\$ \$$ corrected for age of introduction of solid foods, sex, parity, maternal history of allergy, maternal smoking prior to pregnancy, and eczema in $1^{\text {st }}$ year.

\section{Figure legend}

Figure 1A Multivariate analysis showed: food allergen diversity at 6 months $(p=0.01)$ significantly reduced the odds of food allergen sensitization over first 2 years (holding parity $=$ only child, maternal history of allergy $=$ yes, smoking prior to pregnancy $=$ yes, and eczema in 1 st year $=$ yes). Dotted line: $95 \%$ Confidence Interval. Solid line $=$ Predicted Probability.

Figure 1B Multivariate analysis showed: food allergen diversity at 9 months $(\mathrm{p}=0.02)$ significantly reduced the odds of food allergen sensitization over first 2 years (holding parity $=$ only child, maternal history of allergy $=$ yes, smoking prior to pregnancy $=$ yes, and eczema in 1 st year $=$ yes). Dotted line: $95 \%$ Confidence Interval. Solid line $=$ Predicted Probability.

\section{Hosted file}

Figure 1 DD sens PAI 01.04.2021.pdf available at https://authorea.com/users/406426/ articles/517090-dietary-diversity-during-infancy-and-the-association-with-childhoodfood-allergen-sensitization 